\title{
BMJ Open Quality PROMPT Wales project: national scaling of an evidence-based intervention to improve safety and training in maternity
}

\author{
Sophie Renwick (D) , ${ }^{1,2}$ Sarah Hookes, ${ }^{3}$ Tim Draycott, ${ }^{2}$ Madhuchanda Dey, ${ }^{4}$ \\ Frances Hodge, ${ }^{4}$ Jane Storey, ${ }^{2}$ Cathy Winter, ${ }^{2}$ Niladri Sengupta, ${ }^{5}$ Fiona Benjamin ${ }^{6}$
}

To cite: Renwick S, Hookes S, Draycott T, et al. PROMPT Wales project: national scaling of an evidence-based intervention to improve safety and training in maternity. BMJ Open Quality 2021;10:e001280. doi:10.1136/ bmjoq-2020-001280

- Additional supplemental material is published online only. To view, please visit the journal online (http://dx.doi.org/10. 1136/bmjoq-2020-001280).

Received 18 November 2020 Accepted 3 July 2021

Check for updates

(C) Author(s) (or their employer(s)) 2021. Re-use permitted under CC BY-NC. No commercial re-use. See rights and permissions. Published by BMJ.

${ }^{1}$ Faculty of Medicine, University of Bristol, Bristol, UK

${ }^{2}$ PROMPT Maternity Foundation, Bristol, UK

${ }^{3}$ NHS Wales Shared Services

Partnership Legal and Risk

Services, Cardiff, UK

${ }^{4}$ Department of Obstetrics and Gynaecology, Singleton Hospital,

Swansea, UK

${ }^{5}$ Department of Obstetrics and Gynaecology, Betsi Cadwaladr University Health Board,

Bodelwyddan, UK

${ }^{6}$ Department of Obstetrics and Gynaecology, Princess of Wales Hospital, Bridgend, UK

Correspondence to

Dr Sophie Renwick;

sophie.renwick@doctors.org.uk

\section{ABSTRACT}

Background In healthcare, there is increasing recognition of the importance of developing and testing strategies to scale effective interventions. The NHS long-term plan (2019) acknowledges that often a gold standard approach to a problem already exists somewhere within the NHS, however, it has not been replicated widely across the system.

Methods We describe the approach and process measures for national scaling of PROMPT (Practical Obstetric Multi-Professional Training) across 12 obstetricled maternity units in Wales. PROMPT is an evidencebased training package for local maternity staff, previously associated with improvements in maternal and neonatal outcomes, reduction in litigation related to preventable harm and improved safety culture. PROMPT has previously been disseminated internationally using a train-the-trainer model. However, this has been associated with variations in uptake, fidelity and impact. In Wales, the project was supported by Welsh Government, and a structured scaling plan was developed, encompassing ongoing implementation support from a multi-professional team. Results PROMPT was successfully implemented in all obstetric led units in Wales, with 326 local PROMPT facilitators trained, and $82.5 \%-100 \%$ of maternity staff attended a local PROMPT course in the first 15 months of the project (January 2019-March 2020). All training courses included evidence-based authentic elements, and $93 \%$ of courses in the first year (100/107) were supported by a national implementation team, providing coaching, implementation support and quality assurance.

Conclusions Authentically scaling up complex interventions is a significant challenge. To replicate the improved outcomes demonstrated by PROMPT, intervention reach and fidelity must first be demonstrated. In this national scaling project, our scaling methodology led to the successful implementation of PROMPT across all health boards in Wales. Additionally, we demonstrated reduced variation in adoption, reach, timescale and intervention fidelity between maternity units with varying readiness for change, which had been difficult in two previous large-scale PROMPT implementation projects.

\section{INTRODUCTION}

\section{Scaling}

There is increasing recognition of the challenge to effectively spread successful interventions across the NHS. ${ }^{1}$ The Health Foundation has emphasised that healthcare improvement must now focus not only on innovation of solutions, but methods to ensure uptake of these solutions across organisations. ${ }^{2}$ This is echoed in the NHS 2019 longterm plan, which calls for improved scaling of successful interventions. ${ }^{1}$ The WHO describes scaling as 'deliberate efforts to increase the impact of successfully tested health innovations so as to benefit more people and to foster policy and program development on a lasting basis'. ${ }^{3}$ It is a theorised, strategic and systematic approach, ${ }^{45}$ with benefits not just in sharing 'what worked well', but the potential to create widespread networks of implementers, provide a platform for innovation, and large-scale collection and use of data. ${ }^{6}$ Through this, the original intervention may be further improved, honed and evidencebased.

Various scaling frameworks have been developed, ${ }^{6-9}$ however, there remains a lack of consensus on the most effective one to use in the NHS. Effective scaling is not simple, and even evidence-based interventions rarely achieve widespread uptake. ${ }^{10}$ Barriers to scaling include lack of adaptability of the intervention, lack of resources or capacity, insufficient investment in the structure and support of implementation and lack of political will. ${ }^{511-14}$ This paper describes the experience, including barriers and facilitators, of a project to scale a complex healthcare improvement intervention nationally across Wales.

Previous scaling of the Practical Obstetric Multi-Professional Training intervention

PROMPT (Practical Obstetric MultiProfessional Training) is an evidence-based training package for muti-professional maternity staff; involving interactive drills 
and workshops for managing obstetric emergencies, with integrated teamwork and human factors training. ${ }^{15}$ Midwives, obstetricians, anaesthetists and support staff are trained together in their clinical area, using their own equipment and systems. ${ }^{16}{ }^{17}$ Developed in Bristol in the year 2000, PROMPT has been disseminated internationally by the PROMPT Maternity Foundation (PMF) with uptake in diverse healthcare settings including Australia, Germany, Philippines, UAE, USA and Zimbabwe. ${ }^{18-20}$ When implemented successfully, PROMPT has been associated with improvements in maternal and neonatal outcomes in the UK and abroad, including a 50\% reduction in hypoxic ischaemic encephalopathy (HIE), 100\% reduction in permanent brachial plexus injury following shoulder dystocia, a $45 \%$ reduction in school-aged cerebral palsy and $40 \%$ quicker birth at category 1 caesarean section. ${ }^{192-23}$ PROMPT has demonstrated improvements in safety culture in maternity units in Australia, ${ }^{16}$ and reduced litigation costs to hospitals in the UK and USA, through the reduction of preventable harm. ${ }^{1724-26}$

Previously, the method of disseminating PROMPT has employed a centralised, one-off 'train-the-trainer (T3)' programme attended by maternity unit champions who take the intervention tools back to their unit to implement PROMPT locally. ${ }^{18}$ One benefit of a 'cascade' strategy of spread such as this, is that it can result in rapid expansion of interventions, however, it provides little control over the fidelity, and subsequent impact of the intervention at spread sites. ${ }^{27} 28$

Many aspects of the intervention mean PROMPT lends itself well to scaling; it is evidence-based, often demonstrates relative advantage, trialability, observability low risk and local reinvention. ${ }^{2} 10{ }^{29}$ However, the complexity of the 'core' of the intervention is often underestimated by units who perceive it is solely a training programme. Studies by social scientists on the factors that make PROMPT successful have shown it is a complex integrated and systematic approach to improving organisational safety in maternity units, and requires social and system changes in the clinical area, not just the training room. ${ }^{1730}$ For maternity units, the ability to embrace this is influenced by many contextual factors including local leadership, drive, organisational readiness for change, resources and staff buy-in. ${ }^{30}$ These influencing factors are similar to those outlined in Rogers 'diffusion of interventions', where he described a bell-shaped adoption curve for uptake of new interventions, with sites as early adopters, early majority, late majority or laggards. ${ }^{27}$

Due to these differences, it is likely some maternity units need more structure and support than can be provided by the dissemination approach. This is echoed by the variation in implementation across units demonstrated by two previous large-scale projects in Australia and Scotland where PROMPT was implemented by the approach described above, with a single interventionsharing interaction. ${ }^{20} 3233$ In both projects, significant variations in uptake between hospitals were seen, including differences in timescale, reach, adoption and intervention fidelity. ${ }^{20} 3233$ In Scotland, the Thistle study (a step-wedged randomised control trial of national PROMPT implementation) did not achieve significant improvement in its primary outcome of APGAR score $<7$ at 5 min in term infants (APGAR is a standard assessment of newborn condition). The research team recommended that future programmes should provide additional, longitudinal support to maternity units to improve implementation. ${ }^{33}$ Implementation variance is not unique to PROMPT; other scaling projects have identified the need for robust processes and support to be in place to address local barriers. ${ }^{34}$ In this paper, we describe our approach to scale up PROMPT effectively in Wales, including how we designed our implementation methodology to address previous barriers and inconsistencies to scaling identified. We report the process measures from the project, and compare these to the Scottish and Australian projects.

\section{METHODS}

Below, we outline the scaling approach taken for the national roll out of PROMPT across 12 obstetric-led units in Wales.

\section{Scaling method}

The scaling approach for this project was based on the Institute for Healthcare Improvement 'framework for going to full scale ${ }^{7}$ as well as lessons learnt from previous large-scale PROMPT implementation projects, primarily the need for ongoing support including assistance with local planning and adaption of the course, coaching and feedback. ${ }^{1920232533}$ This project represented the transition from a 'help it happen' diffusion mechanism of spread to 'make it happen' planned and regulated approach. ${ }^{10}$

\section{Set-up}

Context

NHS Wales consists of 7 health boards with 12 obstetric-led maternity units. The birth rate is approximately 31000 per annum. Maternity is the leading area for litigation in NHS Wales, with the highest average value of claims. In 2016/2017 maternity cases represented $38 \%$ of the litigation payments reimbursed to health boards. ${ }^{35}{ }^{36}$ Multiprofessional annual training has been recommended by research and several notable reports to reduce preventable harm in maternity, ${ }^{21}{ }^{37-42}$ and has the potential to reduce litigation costs. ${ }^{26}$ In 2016, the chief nursing officer for Wales approached the Maternity Network Wales and the Welsh Risk Pool (WRP) to evaluate the effectiveness of existing obstetric emergency training. A scoping review identified significant variation in quality and methods of training, with teams mainly training in single-profession silos. To improve training, the evidence-based PROMPT programme was selected, via tender, for national implementation. The initiative was entitled 'PROMPT Wales'.

\section{Governance structure}

Previous scaling evaluations have highlighted the need for political support, ensuring interventions are aligned with 
national recommendations. ${ }^{19}$ Therefore the governance structure for this project involved an executive committee composed of PMF, WRP and Maternity Network Wales representatives, who liaised with the Welsh government as well as heads of midwifery and clinical directors at each health board.

The executive committee appointed a national implementation team to work directly with maternity units. This included an obstetrician and midwife from PMF, working in collaboration with multi-professional leads from different health boards (two midwives, four obstetricians and an anaesthetist). Each health board had a local multi-professional team responsible for the delivery of PROMPT.

\section{Initiative goals}

The vision for PROMPT Wales was to reduce avoidable harm and improve perinatal outcomes through multiprofessional training to enhance safety, teamwork and communication. To achieve this, a strategy document was developed by the executive committee, which included four standards:

1. Identification of staff who should participate in PROMPT Wales training.

2. Development of local PROMPT Wales syllabus.

3. Implementation support to maintain local multiprofessional training teams.

4. Multi-professional participation in local PROMPT Wales training.

As part of standard 4, an aspiration of training $100 \%$ of relevant staff by 31 March 2020 was outlined. Welsh government shared these standards with stakeholders of all local health boards through a Welsh Health Circular. ${ }^{43}$ Process outcome measures were set relating to these standards, including faculty data, percentage of staff trained, timescale and course content.

\section{Branding and promotion}

To facilitate ownership, a 'PROMPT Wales' logo was developed and used to brand uniforms and resources. Programme momentum was supported through a website and social media accounts. Stakeholders attended a national launch event where the chief medical officer and chief nursing officer for Wales delivered opening speeches, endorsing the programme and declaring it a priority.

\section{Building a scalable unit}

\section{Adapting the intervention to the context}

Ensuring interventions are aligned with other national incentives is crucial for the feasibility of scaling. ${ }^{7} 1244$ The PROMPT programme aligned with many national projects; such as the Saving Babies Lives care bundle. ${ }^{21}$ However, further adaption of the package was required to compliment the OBS Cymru (obstetric bleeding strategy for Wales) national quality improvement (QI) project, which involved multi-disceplinary team training to reduce post-partum haemorrhage (PPH) rates. ${ }^{45}$
Senior members of the OBS Cymru and PROMPT teams had several collaborative meetings to adapt the PROMPT PPH training module, prior to scaling. Furthermore, OBS Cymru representatives were invited to contribute at the national train-the-trainer programme.

\section{Provision of resources}

In addition to funding training of local teams, WRP ensured all maternity units had the capability to deliver authentic PROMPT via the purchase and distribution of training resources to the health boards. ${ }^{23} 4046$ Local maternity units agreed to fund the release of staff to undertake and attend the training.

\section{Testing scale-up}

Some maternity units in Wales had introduced earlier versions of PROMPT (iteration 1 and 2), however, the scoping exercise demonstrated variety in the content and delivery of courses, especially relating to updated information, multi-professional input and staff trained, therefore all units required transition to the PROMPT Wales model with a more standardised training approach and updated information (iteration 3). The implementation experience gathered from these prior adopters of PROMPT provided valuable feedback for the project. Members of the implementation team were recruited from these 'early adopter' sites. It is beneficial to recruit early adopters as advocates to communicate the value of the intervention to leadership and peers. ${ }^{27}$

\section{Going to full scale}

\section{Introduction of the intervention to sites}

Multi-professional champions (obstetricians, anaesthetists, midwives and support staff) were identified by management from each health board to have responsibility for implementing PROMPT in their units. Eightynine staff attended a T3 course in May/June 2018. This provided facilitation skills training, training aids and strategies for local implementation.

\section{Adoption mechanisms and support systems}

As a result of previous PROMPT scaling projects, the ongoing implementation support role of the implementation team was a crucial element of the scaling plan. Specific actions taken are outlined below.

\section{Planning support and contextual data collection}

Previous work shows scaling is not successful in unreceptive environments; understanding the values, practices and infrastructure of sites is crucial, with adaptation of the intervention where required. ${ }^{710}$ Following the T3 programmes, the implementation team organised unit visits, using a structured template to collect data on staffing, unit structure and previous training practices to understand capacity and capability for scaling. The implementation team reviewed local resources including training venues and equipment, and local course programmes were codeveloped, the content of which was adapted to local training priorities. Information on perceived barriers to scaling 
was gathered from unit teams and additionally, 352 multiprofessional staff completed an anonymised Sexton Safety Attitude Questionnaire prior to local implementation, to help with understanding individual unit issues with teamwork, safety climate, perception of management, job satisfaction, working conditions and stress recognition 232547 and therefore personalise support.

\section{Training of additional faculty}

During planning visits, all local teams raised concerns about achieving PROMPT Wales standards without expanding their core of local trainers, due to the challenge of releasing facilitators from clinical duties. Therefore, the implementation team supported units to organise and deliver local 'faculty development programmes' to train additional faculty in each unit prior to commencing courses.

\section{Creating networks}

Peer networks are a key component of facilitating change in practice. ${ }^{3}$ The implementation team used social media, newsletters, conference presentations and a website to share programme progress. The national launch event included networking and troubleshooting sessions for local teams, and in February 2020 (after a year of local implementation), the implementation team organised a further networking event to reflect and share local barriers and enablers for the programme.

\section{Engaging leaders}

It is important to not only inform leaders, but to coach them regarding the specific actions required to successfully adopt the intervention. ${ }^{18} 1927$ The implementation team presented to the National Specialist Advisory Group and head of midwifery advisory group (HOMAG) in 2019 , communicating the value of the programme and informing stakeholders how they could support PROMPT locally.

\section{Coaching and support}

Building a bond between implementers and adoptees often has a positive influence on implementation. ${ }^{27} 48$ Multi-professional implementation team members provided face-to-face coaching and support on courses, chaired a debrief session and providing written feedback and action plans to local teams.

\section{Setting up monitoring processes}

Local teams submitted training data for monitoring of progress towards the PROMPT Wales standards. The implementation team fed back training data, observational data and reports to the executive committee. A set of baseline clinical outcomes was developed including rates of postpartum haemorrhage, APGAR score $<7$ at 5 min, HIE, maternal admission to level 3 care, unexpected neonatal intensive care unit (NICU) admission at term and brachial plexus injury at birth. They examined ways of collecting and monitoring this data including local and national data collection processes.

\section{Process measures}

Previous research has identified the clinical impact of PROMPT when it is implemented authentically, however, clinical outcome changes have previously taken at least 2 years to be demonstrable following the commencement of training, and therefore post implementation outcomes are not included in this paper. ${ }^{19} 2033$ Process measures can ensure an evidence-based intervention is being delivered as intended, and therefore, we report on process outcomes of the scaling methodology used in PROMPT Wales, including:

1. Adoption and reach of the intervention: defined by the number of local faculty trained, number of maternity units that initiated local courses, percentage of eligible staff (midwives, obstetricians and obstetric anaesthetists) who attended a course in the first 15 months. These data were gathered by the implementation team through training registry data and feedback forms, observational data and staffing information from human resources and managers.

2. Authenticity: course content evaluated against evidence-based elements of PROMPT. Quality assurance is defined by number of courses attended by members of national implementation (NI) team. Data were gathered through analysis of course programmes and observational reports and notes made by the multiprofessional implementation team.

3. Timescale of replication-days from T3 to initiation of local courses.

Analysis of number of staff trained was done using simple statistics and percentages.

\section{Ethical considerations}

As this is a quality improvement and implementation report with observational process data, formal ethical approval was not required. Maternity units and individuals were anonymised in any reports outside of the NIteam. Patients were not involved in this project, therefore patient and public involvement for design was not applicable.

\section{RESULTS}

\section{PROMPT Wales trained faculty}

Eighty-nine multi-professional faculty were trained during the centralised T3 programmes, including 29 midwives, 23 obstetricians, 18 anaesthetists and 19 allied professionals. Following this, 7 local faculty development programmes trained an additional 173 faculty. By January 2019, there were 262 trained local facilitators (see online supplemental material). During 2019 two further national T3 programmes were conducted, with a total of 326 trained facilitators by January 2020.

\section{Timescale}

Seven units had some experience with PROMPT prior to the project and $5 / 7$ (units $4,5,6,7,8$ ) were already running courses. However, their current training practices required transition to the PROMPT Wales model. $2 / 7$ (units 11,12 ) required restructuring of their training 


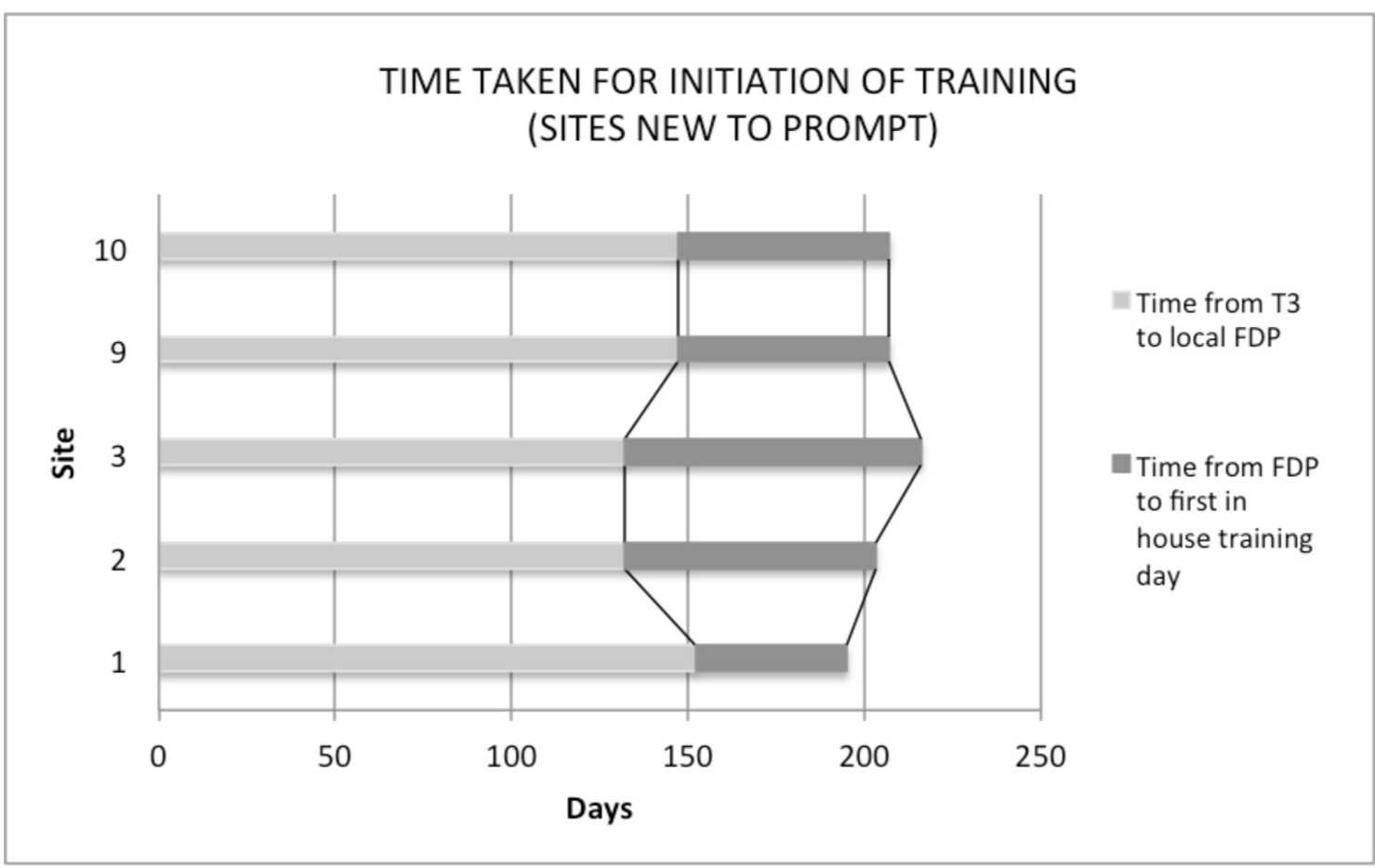

Figure 1 Timescale for initiation of local training for five units new to Practical Obstetric Multi-Professional Training. FDP, faculty development programme; T3, train the trainer.

systems and initiated their new course 111 days after T3. For the five units who had no prior experience of PROMPT (units 1, 2, 3, 9, 10), the timeline from T3 to local implementation is outlined in figure 1.

By January 2019 all 12 maternity units had initiated regular courses. Course frequency varied from 5 to 13 per annum, with an average of 20-30 participants.

\section{Staff trained}

Two thousand eight hundred and ten staff were identified requiring training nationally, including midwives (1676), obstetricians (299) obstetric anaesthetists (368) and healthcare assistants (467). A total of 141 local courses were held from January 2019-March 2020 (107 in 2019). During this 15 -month time period, $94 \%$ of midwives, $90 \%$ of obstetricians, $86 \%$ of anaesthetists and $77 \%$ of healthcare assistants attended a course. The mean attendance for midwives, obstetricians and obstetric anaesthetists was $90.7 \%$ (88.6\% when including healthcare assistants, however previous research of PROMPT demonstrating improved outcomes has not included their attendance) and figure 2 describes the breakdown per health board.

\section{Intervention fidelity}

Research in to obstetric emergency training packages have shown that to achieve improvements in outcomes, training packages must have the following core components ${ }^{162049}$ :

- Multi-professional (participants and trainers).

- Locally delivered-in the clinical area to familiarise staff with local systems and processes.

- Training all maternity staff annually—including obstetricians, anaesthetists and midwives.
- Integrated team working and human factors training.

- 'Right fidelity' simulation, for example, for shoulder dystocia.

In 2019, 100/107 (93\%) of local courses were observed by members of the implementation team for quality control and monitoring processes, and table 1 summarises the authenticity of training content of each unit.

\section{Cost}

The expenditure of the WRP on the scaling of PROMPT Wales for the financial year 2018/2019 was £375000. This included set-up and implementation costs including funded time for the NI team, events and resources including specialist mannikins and training materials. This cost is not negligible, however, is modest compared with the litigation costs in maternity. The total cost of reimbursements for maternity claims for concluded cases was $£ 19$ million in $2016 / 2017$, and $£ 17$ million in 2019/2020. In addition, £8 million per annum is spent making periodical payments to claimants. The average reimbursement per case in 2017 was $£ 400000,,^{35}$ if the investment in PROMPT Wales leads to prevention of at least one significant adverse outcome nationally, it may be viewed as financially sound.

\section{DISCUSSION}

The PROMPT Wales programme provides valuable insights into the national scaling of an evidence-based complex training intervention. Comparators have been provided by the THISTLE study in Scotland (12 units) ${ }^{32} 33$ and implementation in Victoria, Australia (8 units $)^{20}$ where a dissemination approach to spread was 
Total percentage of staff who attended PROMPT Wales training

$1 / 1 / 19-31 / 3 / 20$ (per health board A-G)

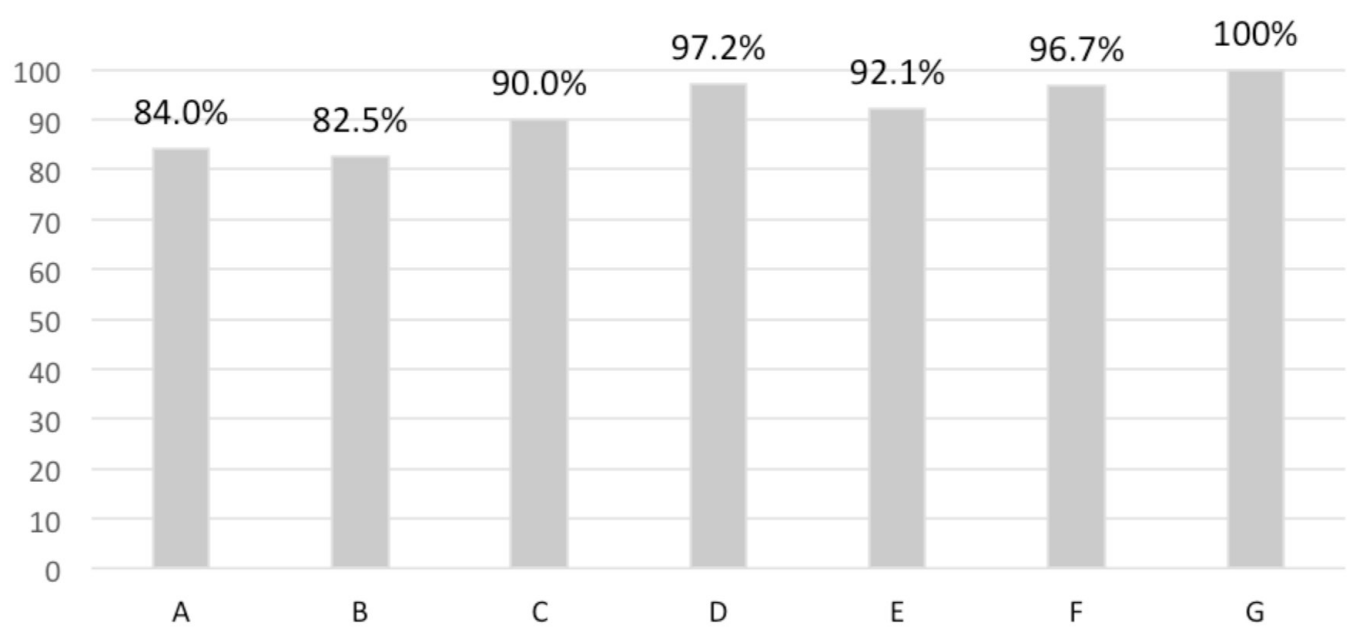

Figure 2 Percentage of staff per health board who attend a Practical Obstetric Multi-Professional Training (PROMPT) Wales course January 2019-March 2020 (excluding staff groups that were not mandated e.g.health care assistants, theatre staff and students).

used, with a single 'T3' interaction. The key differences in PROMPT Wales have been provision of support from Welsh government, a clear governance structure, national standards and accountability for units and ongoing support and monitoring.

In Wales, there was a reduction in variation of time taken for units new to PROMPT to initiate training; the range for the five units was 21 days (195-216), compared with 186 days (1-186) in Victoria ${ }^{20}$ and 487 days (30-517) in Scotland (figure 3) ${ }^{32} 33$ In both Victoria and Scotland, there was significant variation in the number of trained faculty, number of staff trained and course frequency per unit. In Victoria, trained faculty varied from 1 to
13 per unit, and course frequency was $0-6$ per annum (mean 3.5). Only $51 \%$ of all possible staff were trained in the first year of the programme $(21 \%-100 \%$ across sites, with one site not initiating training). ${ }^{33}$ In Scotland, course frequency was 1-20 per annum, number of staff trained per course 6-30 participants (mean 20.75) and total number of staff trained per unit 24-365 in the first year. There are no data available on what proportion of eligible staff this represents, however, all maternity units will have $>24$ staff, so we may assume some units had a low proportion trained. ${ }^{33}$ Although initiation of training took longer for some PROMPT Wales units (figure 3), the main barrier was the requirement for additional faculty

\begin{tabular}{|c|c|c|c|c|c|}
\hline $\begin{array}{l}\text { Obstetric } \\
\text { unit }\end{array}$ & $\begin{array}{l}\text { Faculty multi- } \\
\text { professional on each } \\
\text { training day }\end{array}$ & $\begin{array}{l}\text { Participants multi- } \\
\text { professional on each } \\
\text { training day }\end{array}$ & $\begin{array}{l}\text { Training delivered in } \\
\text { clinical area }\end{array}$ & $\begin{array}{l}\text { Formal teamwork and human } \\
\text { factors lecture and integrated } \\
\text { training }\end{array}$ & $\begin{array}{l}\text { Shoulder dystocia using } \\
\text { high fidelity mannequin }\end{array}$ \\
\hline 2 & Yes & Yes & Yes & Yes & Yes \\
\hline 3 & Yes & Yes & Yes & Yes & Yes \\
\hline 6 & Yes & Yes & Yes & Yes & Yes \\
\hline 7 & Yes & Yes & Yes & Yes & Yes \\
\hline 8 & Yes & Yes & Yes & Yes & Yes \\
\hline 9 & Yes & Yes & Yes & Yes & Yes \\
\hline Total & $12 / 12$ & $12 / 12$ & $10 / 12$ & $12 / 12$ & $12 / 12$ \\
\hline
\end{tabular}

*Unit 11 and 12 underwent their training together in a simulation centre as a temporary measure due to planned changes for unit 12 to become a midwifery led unit. After November 2019, training took place on site. 


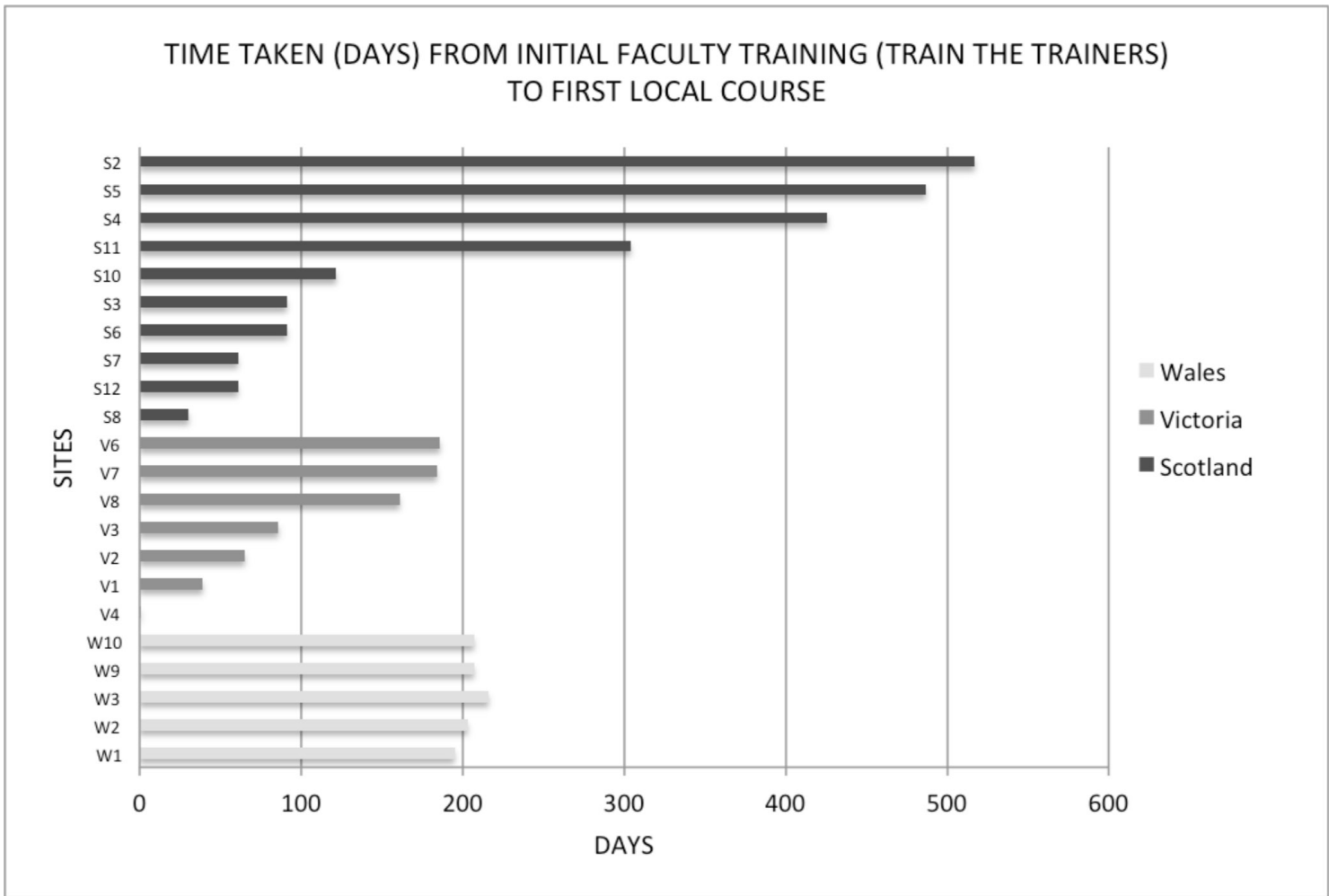

Figure 3 Comparison of time take to initiate local Practical Obstetric Multi-Professional Training following train the trainers course for Wales, Victoria and Scotland.

to meet the PROMPT Wales standards; training $100 \%$ of staff annually and maintaining a multi-professional faculty on every training course. Once additional faculty were trained, local initiation was accomplished within a comparatively short period of time; 43-84 days (mean 63.6). Additionally, in Scotland, the researchers identified variation in course content, and therefore, intervention fidelity. ${ }^{33}$ In Wales, all units included the core elements of PROMPT and authenticity of intervention was monitored by the implementation team.

The insights offered by Rogers 'Diffusion of Interventions' mentioned in section 01.2 may be a useful heuristic to understand the implementation of PROMPT. ${ }^{27}$ Standard dissemination at scale has previously resulted in a heterogeneous and variable intervention adoption, perhaps due to lack of additional support or motivation for units who may be late majority or laggards. ${ }^{50}$ The scaling method used for PROMPT Wales, including national level system implementation and support, reduced variety in implementation process measures between units. Although the aspiration for $100 \%$ of all relevant staff attending a local PROMPT Wales course by March 2020 was not achieved, all health boards were close to this achievement $(82.5 \%-100 \%)$.

\section{Barriers and facilitators to implementation}

The consolidated framework for implementation research $(\mathrm{CFIR})^{29}$ provides a pragmatic framework for considering influencers of implementation. In table 2 , the domains of the CFIR are used to describe the facilitators to PROMPT
Wales implementation identified by the implementation team, which will be of benefit to other groups designing their scaling strategy. Despite working with units with varying prior experience of PROMPT, we did not find significant additional challenges in 'brownfield' sites compared with 'greenfield' sites, perhaps helped by our early engagement with key leaders from existing PROMPT units, and invitation for them to join the national implementation team as peer educators.

The key barriers to implementation were:

1. Release of obstetric and anaesthetic faculty from clinical duties, as there was no centralised funding available to units for staff time. Although the implementation team communicated the value of financially supporting the training to management, the pressure on clinicians not to cancel activities varied between sites.

2. Requirement to train additional faculty to meet PROMPT Wales standards due to difficulty releasing staff-if we had investigated the number of local facilitators required to achieve the PROMPT Wales standards pre-T3, we could have trained more faculty, thereby preventing delay.

3. Availability of training rooms for lecture elements of the course-often these were booked out months in advance, leading to delays in getting training courses organised.

There were a number of limitations to the project; first, research design meant we were unable to provide a control group for comparison of scaling methodology. 
Table 2 Facilitators to the PROMPT intervention based on the consolidated framework for implementation research

\begin{tabular}{|c|c|c|}
\hline Domain & Constructs & PROMPT Wales facilitating factors \\
\hline $\begin{array}{l}\text { Characteristics } \\
\text { of the } \\
\text { intervention }\end{array}$ & $\begin{array}{l}\text { 1. Intervention source. } \\
\text { 2. Evidence strength and quality. } \\
\text { 3. Relative advantage. } \\
\text { 4. Adaptability. } \\
\text { 5. Trialability. } \\
\text { 6. Complexity. } \\
\text { 7. Design, quality and packaging. } \\
\text { 8. Cost. }\end{array}$ & $\begin{array}{l}\text { Local adaption on the intervention - to encourage local ownership. } \\
\text { Robust evidence for intervention - multiple publications showing PROMPT effect on clinical } \\
\text { outcomes. } \\
\text { Peer endorsement-anecdotal stories from PROMPT Wales implementation team who had prior } \\
\text { experience with PROMPT, benefit of engaging 'peer educators'. } \\
\text { Professional branding of tools and resources. } \\
\text { Standardised implementation tools and guidance. } \\
\text { Funding - 'Starter pack' training and resources funded by the Welsh Risk Pool. }\end{array}$ \\
\hline
\end{tabular}
Welsh government to implement PROMPT.

\begin{tabular}{|c|c|c|}
\hline Inner setting & $\begin{array}{l}\text { 1. Structural characteristics. } \\
\text { 2. Networks and communications. } \\
\text { 3. Culture. } \\
\text { 4. Implementation climate. }\end{array}$ & $\begin{array}{l}\text { Supporting local team working and communication-the implementation team organised and } \\
\text { chaired local team meetings and phone calls, supporting the team to bond and work together more } \\
\text { effectively. Communication channels between local teams were encouraged (PROMPT Wales team } \\
\text { text and email groups). } \\
\text { Implementation support tailored to unit needs-culture assessed by SAQs and planning discussions } \\
\text { with local teams to identify local issues, tailoring of support to address these. } \\
\text { Course observations and structure feedback - to provide praise as well as clear and measurable } \\
\text { improvement goals during implementation process. }\end{array}$ \\
\hline $\begin{array}{l}\text { Individuals } \\
\text { involved }\end{array}$ & $\begin{array}{l}\text { 1. Knowledge and beliefs about the } \\
\text { intervention. } \\
\text { 2. Self-efficacy. } \\
\text { Individual stage of change } \\
\text { 1. Individual identification with } \\
\text { organisation. } \\
\text { 2. Other personal attributes. }\end{array}$ & $\begin{array}{l}\text { Careful selection of local champions - local faculty were nominated by management, those who } \\
\text { showed enthusiasm and had prior experience of training were put forward. } \\
\text { Building a partnership between implementation team and maternity unit - via face-to-face support } \\
\text { and regular check-ins. } \\
\text { Assessing readiness for change-this was assessed by implementation planning session on T3 and } \\
\text { at initial unit visits. } \\
\text { Troubleshooting -implementation team listened and acknowledged concerns about achieving } \\
\text { implementation goals and tailored support to local teams. They shared learning and acted as the 'go } \\
\text { between' for local teams, their managers and the executive committee. } \\
\text { Positive reinforcement - use of 'PROMPT Stars' to recognise individual contributions and excellence. }\end{array}$ \\
\hline
\end{tabular}

$\mathrm{NI}$ team (National Implementationteam)-a multiprofessional team of obstetricians midwives and anaesthetists from the PROMPT Maternity Foundation and NHS Wales hospitals who supported local teams with implementation.

HOMAG, Head of Midwifery Advisory Group; NSAG, National Specialist Advisory Group; PROMPT, Practical Obstetric Multi-Professional Training; SAQ, Sexton Safety Attitude Questionnaire; T3, train-the-trainer.

Furthermore, process data was self-reported, however units had to submit evaluation forms as proof of staff attendance.

\section{CONCLUSIONS}

This national scaling project led to the successful implementation of PROMPT across all health boards in NHS Wales, with $82.5 \%-100 \%$ of all eligible midwives, obstetricians and anaesthetists trained between January 2019 and March 2020. Additionally, the scaling methods reduced the variation in adoption, reach, timescale and authenticity of implementation between units, previously identified as a challenge in large-scale PROMPT implementation projects. The authors feel this was driven by a deliberate and structured scaling approach, with an implementation team providing longitudinal support, monitoring and networking for maternity units, accountability with national standards and sponsorship by Welsh Government. WRP continues to fund a smaller sustainability team and PROMPT Wales remains high on the national agenda; recognised in the Welsh Governments' 'Five year vision for the future' (2019-2024).

We recommend that future scaling projects should include funded time for implementation champions at sites. Additionally, comprehensive planning preimplementation is crucial for efficient and effective scaling. This project has provided valuable insight into the organisational structures and processes required to 
implement a complex intervention on a national scale in maternity, and lessons learnt could assist future scaling projects for complex interventions.

Correction notice This article has been corrected since it first published. The contributors statement has been updated.

Acknowledgements We would like to acknowledge the hard work and dedication that was played by local PROMPT Wales teams in implementing PROMPT Wales.

\section{Collaborators Jonathan WebbSarah Morris.}

Contributors All named authors were members of the PROMPT Wales Executive committee (CW, TD) or National Implementation Team (SR, SH, JS, NS, MD, FH, FB) and were responsible for devising and executing the implementation strategy, along with Sarah Morris, Implementation Midwife. SR is responsible for the overall content as the guarantor, performed the literature searches behind the scaling approach, drafted and revised this paper with input from the rest of the authors, and collected and analysed process measure data in regard to timescale, authenticity and faculty trained. Process measure data was collated by SH, principally staff training information from each health board. We would like to acknowledge the contribution of Neil Muchatuta for his role in the National Implementation Team and support of maternity units. We would also like to acknowledge the contribution of Jonathan Webb to this work, in his position as Head of Welsh Risk Pool for NHS Wales Shared Services Partnership, and Claire Davies from Maternity Network Wales. Local maternity unit PROMPT champions from all health boards in Wales were instrumental in this project, and we would like to acknowledge their contribution via local implementation of the intervention, and providing data with the authors.

Funding NHS Wales Shared Services Partnership, Legal and Risk Services funded staff training, implementation support and training materials for this project.

\section{Competing interests None declared.}

Patient consent for publication Not required.

Ethics approval According to the policy activities that constitute research from Health Care and Research Wales, this work met criteria for operational improvement activities exempt from ethics review.

Provenance and peer review Not commissioned; externally peer reviewed.

Supplemental material This content has been supplied by the author(s). It has not been vetted by BMJ Publishing Group Limited (BMJ) and may not have been peer-reviewed. Any opinions or recommendations discussed are solely those of the author(s) and are not endorsed by BMJ. BMJ disclaims all liability and responsibility arising from any reliance placed on the content. Where the content includes any translated material, BMJ does not warrant the accuracy and reliability of the translations (including but not limited to local regulations, clinical guidelines, terminology, drug names and drug dosages), and is not responsible for any error and/or omissions arising from translation and adaptation or otherwise.

Open access This is an open access article distributed in accordance with the Creative Commons Attribution Non Commercial (CC BY-NC 4.0) license, which permits others to distribute, remix, adapt, build upon this work non-commercially, and license their derivative works on different terms, provided the original work is properly cited, appropriate credit is given, any changes made indicated, and the use is non-commercial. See: http://creativecommons.org/licenses/by-nc/4.0/.

\section{ORCID iD}

Sophie Renwick http://orcid.org/0000-0001-6022-3175

\section{REFERENCES}

1 Alderwick H, Dixon J. The NHS long term plan, 2019. Available: https://www.longtermplan.nhs.uk [Accessed 17 Oct 2020].

2 Horton T, Illingworth J, Warburton W. The spread challenge: how to support the successful uptake of innovations and improvements in health care. London: Health Foundation, 2018.

3 World Health Organization (WHO), WHO Regional Office for Europe. Scaling up projects and initiatives for better health: from concepts to practice, 2016. Available: https://www.euro.who.int/en/publications [Accessed 21 Dec 2020].

4 Fixsen DL, Blase KA, Fixsen AAM. Scaling effective innovations. Criminol Public Policy 2017;16:487-99.

5 Norton W, Mittman BS. Scaling-up health promotion/disease prevention programs in community settings: barriers, facilitators, and initial recommendations. Report submitted to patrick and catherine weldon donaghue medical research foundation. Available: www. donaghue.org [Accessed 27 Nov 2020].

6 Ben Charif A, Zomahoun HTV, LeBlanc A, et al. Effective strategies for scaling up evidence-based practices in primary care: a systematic review. Implement Sci 2017;12:139-13.

7 Barker PM, Reid A, Schall MW. A framework for scaling up health interventions: lessons from large-scale improvement initiatives in Africa. Implement Sci 2016;11:12-11.

8 Milat AJ, Bauman A, Redman S. Narrative review of models and success factors for scaling up public health interventions. Implement Sci 2015;10:113.

9 Yamey G. Scaling up global health interventions: a proposed framework for success. PLoS Med 2011;8:e1001049.

10 Greenhalgh T, Robert G, Macfarlane F, et al. Diffusion of innovations in service organizations: systematic review and recommendations. Milbank Q 2004;82:581-629.

11 Mangham LJ, Hanson K. Scaling up in international health: what are the key issues? Health Policy Plan 2010;25:85-96.

12 Greenhalgh T, Papoutsi C. Spreading and scaling up innovation and improvement. BMJ 2019;365:I2068.

13 Milat AJ, King L, Bauman AE, et al. The concept of scalability: increasing the scale and potential adoption of health promotion interventions into policy and practice. Health Promot Int 2013;28:285-98.

14 Berelowitz D, Richardson M, for MTIC. Realising the potential of social replication, 2013. Available: https://www.springimpact.org [Accessed 02 Sep 2020].

15 Winter C, Crofts J, Draycott T. PROMPT course manual. Cambridge University Press, 2017. ISBN: 9781108430296.

16 Strachan B, Crofts J, James M. Proof of principle study of the effect of individual and team drill on the ability of labour ward staff to manage acute obstetric emergencies. In: Safe (simulation and firedrill evaluation) study report to the department of health. 67906788 , 2008.

17 Macrae C. Delivering high reliability in maternity care: in situ simulation as a source of organisational resilience. Safety Science 2016;2016:490-500.

18 Crofts JF, Mukuli T, Murove BT, et al. Onsite training of doctors, midwives and nurses in obstetric emergencies, Zimbabwe. Bull World Health Organ 2015;93:347-51.

19 Weiner CP, Collins L, Bentley S, et al. Multi-professional training for obstetric emergencies in a U.S. hospital over a 7-year interval: an observational study. J Perinatol 2016;36:19-24.

20 Shoushtarian M, Barnett M, McMahon F, et al. Impact of introducing practical obstetric multi-professional training (prompt) into maternity units in Victoria, Australia. BJOG 2014;121:1710-8.

21 Robertson L, Knight H, Prosser Snelling E, et al. Each baby counts: national quality improvement programme to reduce intrapartumrelated deaths and brain injuries in term babies. Semin Fetal Neonatal Med 2017;22:193-8.

22 Siassakos D, Bristowe K, Draycott TJ, et al. Clinical efficiency in a simulated emergency and relationship to team behaviours: a multisite cross-sectional study. BJOG 2011;118:596-607.

23 Draycott TJ, Crofts JF, Ash JP, et al. Improving neonatal outcome through practical shoulder dystocia training. Obstet Gynecol 2008;112:14-20.

24 Collins KJ, Draycott TJ. Skills and drills: are they worth the effort? Obstet Gynaecol Reprod Med 2015;25:372-4.

25 Draycott T, Sibanda T, Owen L, et al. Does training in obstetric emergencies improve neonatal outcome? BJOG 2006;113:177-82.

26 Authority NALNL. Ten years of maternity claims: an analysis of NHS litigation authority data, 2012. Available: https://resolution.nhs.uk/ resources [Accessed 17 Oct 2020].

27 Rogers EM. Diffusion of innovations. 5th edn. New York: Free Press, 2003.

28 Kirkpatrick JD, Kirkpatrick WK. Kirkpatrick's four levels of training evaluation. ATD Press, 2016.

29 Damschroder LJ, Aron DC, Keith RE, et al. Fostering implementation of health services research findings into practice: a consolidated framework for advancing implementation science. Implement Sci 2009;4:50.

30 Liberati EG, Tarrant C, Willars J, et al. How to be a very safe maternity unit: an ethnographic study. Soc Sci Med 2019;223:64-72.

31 Collins K, Moore A. Understanding the implementation of obstetric emergency training: the THISTLE-Plus study. Cape Town, South Africa: RCOG World Congress, 2017: 43-4.

32 Lenguerrand E, Winter C, Innes K, et al. Thistle: trial of hands-on interprofessional simulation training for local emergencies: a research protocol for a stepped-wedge clustered randomised controlled trial. BMC Pregnancy Childbirth 2017;17:294. 
33 Lenguerrand E, Winter C, Siassakos D, et al. Effect of handson interprofessional simulation training for local emergencies in Scotland: the thistle stepped-wedge design randomised controlled trial. BMJ Qual Saf 2020;29:122-34.

34 Ellis D, Crofts JF, Hunt LP, et al. Hospital, simulation center, and teamwork training for eclampsia management: a randomized controlled trial. Obstet Gynecol 2008;111:723-31.

35 MWJFA-L R. Legal and risk Services \& Welsh Risk Pool Services Annual Review 2016/2017

36 Yau CWH, Leigh B, Liberati E, et al. Clinical negligence costs: taking action to safeguard NHS sustainability. BMJ 2020;368:m552.

37 NHS England. Better births: improving outcomes of maternity services in England. A five year forward view for maternity care. first published 22nd February 2016, page updated 22ndAugust 2017. Available: https://www.england.nhs.uk/publication/better-birthsimproving-outcomes-of-maternity-services-in-england-a-five-yearforward-view-for-maternity-care [Accessed 02 Sep 2020].

38 Magro M. Five years of cerebral palsy claims: a thematic review of NHS resolution data, 2017. Available: https://resolution.nhs.uk/ wp-content/uploads/2017/09/Five-years-of-cerebral-palsy-claims_ A-thematic-review-of-NHS-Resolution-data.pdf [Accessed 17 Nov 2020].

39 Siassakos D, Hasafa Z, Sibanda T, et al. Retrospective cohort study of diagnosis-delivery interval with umbilical cord prolapse: the effect of team training. BJOG 2009;116:1089-96.

40 Crofts JF, Lenguerrand E, Bentham GL. Prevention of brachial plexus injury-12 years of shoulder dystocia training: an interrupted timeseries study. BJOG. John Wiley \& Sons, Ltd 2016;123:111-8.

41 Kirkup B. The report of the Morecambe Bay investigation: an independent investigation into the management, delivery and outcomes of care provided by the maternity and neonatal services at the university hospitals of Morecambe Bay NHS Foundation trust from January 2004 to June 2013, 2015. Available: https://www.gov. uk/government/publications [Accessed 19 Nov 2020].

42 Knight M, Tuffnell D, Kenyon S. MBRRACE-UK. saving lives, improving mothers' care-surveillance of maternal deaths in the UK, 2015. Available: https://www.npeu.ox.ac.uk/mbrrace-uk/reports [Accessed 14 Oct 2020].

43 Government HW. Welsh health circular: implementation of prompt standards in maternity services in Wales, 2019: 1-3.

44 Milat AJ, Newson R, King L, et al. A guide to scaling up population health interventions. Public Health Res Pract 2016;26:e2611604.

45 Bell SF, Kitchen T, John M, et al. Designing and implementing an al Wales postpartum haemorrhage quality improvement project: OBS Cymru (the obstetric bleeding strategy for Wales). BMJ Open Qual 2020;9:e000854.

46 Crofts JF, Bartlett C, Ellis D, et al. Training for shoulder dystocia: a trial of simulation using low-fidelity and high-fidelity mannequins. Obstet Gynecol 2006;108:1477-85.

47 Sexton JB, Helmreich RL, Neilands TB, et al. The safety attitudes questionnaire: psychometric properties, benchmarking data, and emerging research. BMC Health Serv Res 2006;6:44.

48 Ilott I, Gerrish K, Pownall S, et al. Exploring scale-up, spread, and sustainability: an instrumental case study tracing an innovation to enhance dysphagia care. Implement Sci 2013;8:128-7.

49 Siassakos D, Crofts JF, Winter C, et al. The active components of effective training in obstetric emergencies. BJOG 2009;116:1028-32.

50 Rossom RC, Solberg LI, Magnan S, et al. Impact of a national collaborative care initiative for patients with depression and diabetes or cardiovascular disease. Gen Hosp Psychiatry 2017;44:77-85. 